University of Nebraska - Lincoln

DigitalCommons@University of Nebraska - Lincoln

Agronomy \& Horticulture -- Faculty Publications

Agronomy and Horticulture Department

2018

\title{
Management and Modeling of Winter-time Basil Cultivars Grown with a Cap MAT System
}

George E. Meyer

University of Nebraska-Lincoln, gmeyer1@unl.edu

M. Elizabeth Conley

University of Nebraska-Lincoln, mconley2@unl.edu

Ellen T. Paparozzi

University of Nebraska-Lincoln, etp1@unl.edu

Follow this and additional works at: https://digitalcommons.unl.edu/agronomyfacpub

Part of the Agricultural Science Commons, Agriculture Commons, Agronomy and Crop Sciences Commons, Botany Commons, Horticulture Commons, Other Plant Sciences Commons, and the Plant Biology Commons

Meyer, George E.; Conley, M. Elizabeth; and Paparozzi, Ellen T., "Management and Modeling of Winter-time Basil Cultivars Grown with a Cap MAT System" (2018). Agronomy \& Horticulture -- Faculty Publications. 1109.

https://digitalcommons.unl.edu/agronomyfacpub/1109

This Article is brought to you for free and open access by the Agronomy and Horticulture Department at DigitalCommons@University of Nebraska - Lincoln. It has been accepted for inclusion in Agronomy \& Horticulture -Faculty Publications by an authorized administrator of DigitalCommons@University of Nebraska - Lincoln. 


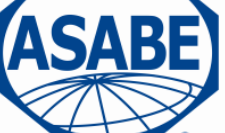

An ASABE Meeting Presentation

DOI: 10.13031/aim.201701398

Paper Number: 1701398

2950 Niles Road, St. Joseph, MI 49085-9659, USA

269.429.0300 fax 269.429.3852 hq@asabe.org www.asabe.org

\title{
Management and Modeling of Winter-time Basil Cultivars Grown with a Cap MAT System
}

\author{
George E. Meyer \\ Biological Systems Engineering \\ M. Elizabeth Conley \\ Agronomy and Horticulture \\ Ellen T. Paparozzi \\ Agronomy and Horticulture \\ University of Nebraska, Lincoln, NE \\ Written for presentation at the \\ 2017 ASABE Annual International Meeting \\ Sponsored by ASABE \\ Spokane, Washington \\ July 16-19, 2017
}

The authors are solely responsible for the content of this meeting presentation. The presentation does not necessarily reflect the official position of the American Society of Agricultural and Biological Engineers (ASABE), and its printing and distribution does not constitute an endorsement of views which may be expressed. Meeting presentations are not subject to the formal peer review process by ASABE editorial committees; therefore, they are not to be presented as refereed publications. Publish your paper in our journal after 
successfully completing the peer review process. See www.asabe.org/JournalSubmission for details. Citation of this work should state that it is from an ASABE meeting paper. EXAMPLE: Author's Last Name, Initials. 2017. Title of presentation. ASABE Paper No. --. St. Joseph, MI.: ASABE. For information about securing permission to reprint or reproduce a meeting presentation, please contact ASABE at www.asabe.org/permissions (2950 Niles Road, St. Joseph, MI 49085-9659 USA).

ABSTRACT Basil (Ocimum basilicum) is a high value crop, currently grown in the field and greenhouses in Nebraska. Winter-time, greenhouse studies were conducted during 2015 and 2016, focusing on cultivars of basil grown on a Cap MAT II ${ }^{\circledR}$ system with various levels of fertilizer application. The goal was to select high value cultivars that could be grown in Nebraska greenhouses. The studies used water content, electrical conductivity, photosynthetically active radiation (PAR), and relative humidity, air and soil media temperature sensors.

Greenhouse systems can be very complex, even though controlled by mechanical heating and cooling. Uncertain or ambiguous environmental and plant growth factors can occur, where growers need to plan, adapt, and react appropriately. Plant harvest weights and electronic sensor data was recorded over time and used for training and internally validating fuzzy logic inference and classification models. Studies showed that GENFIS2 'subtractive clustering' of data, prior to ANFIS training, resulted in good correlations for predicted growth $\left(\mathrm{R}^{2}>0.85\right)$, with small numbers of effective rules and membership functions. Cross-validation and internal validation studies also showed good correlations $\left(\mathrm{R}^{2}>0.85\right)$. Decisions on basil cultivar selection and forecasting as to how quickly a basil crop will reach marketable size will help growers to know when to harvest, for optimal yield and predictable quantity of essential oils. If one can predict reliably how much essential oil will be produced, then the methods and resultant products can be proposed for USP or FDA approval. Currently, most plant medicinal and herbal oils and other supplements vary too widely in composition for approval. The use of fuzzy set theory could be a useful mathematical tool for plant and horticultural production studies.

Keywords: greenhouses, winter, basil, cultivars, crop growth, mathematical models. 


\section{Introduction}

Nebraska is a major agricultural crop production state, producing more than 1.7 billion bushels of corn and 314 million bushels of soybeans, respectively in 2016 (Nebraska 2016 state agriculture overview). In addition, Nebraska is one of the top three edible dry bean, popcorn and millet producers in the nation. This success is due to abundant sunshine, warm temperatures, and plentiful moisture, during the May through October growing season. However, what is not well known is that abundant sunshine can occur during the winter months in Nebraska. This extensive amount of winter-time solar energy has yet to be fully exploited in Controlled Environment Agriculture (CEA) and turned into additional food production enterprises. Research by Hoagland, et al (2008) showed that the average corn/soybean farmer has sufficient available labor and/or time available from December through March for additional activities. This time could be utilized to grow alternate crops in greenhouses.

A plant called basil (Ocimum spp.) is a popular annual culinary and medicinal herb, and contains essential oils and useable compounds, such as linalool, eugenol, and methyl chavicol. However, most studies involved field grown basil during the summer. Various researchers have studied the effects of fertilizer on the growth, dry matter and oil yield of field grown basil. However, the production of basil in a Nebraska greenhouse had not been widely studied, until recently (Wan, 2016 and Osborn, et al, 2016).

A basic research question has been which basil cultivars, as there are many, are best for greenhouse production. Predicting how quickly a potted basil plant will reach marketable size (100 g of dry weight) could help growers know when to harvest basil or any medicinal plant grown in a greenhouse. Prediction of plant essential oils would assist USP or FDA certification (depending on the active ingredient). The quantity of essential oils is correlated with plant dry matter yield. Currently, most plant medicinal and herbal oils and other supplements are unknown or vary too widely in composition for certification approval. Research studies could help change that situation.

Greenhouse production of Basil requires an efficient bench system. The performance of the Cap Mat II ${ }^{\mathrm{TM}}$ (Hummert International, St. Louis, MO) capillary fertigation system for greenhouses has been found to be highly successful during previous winter time greenhouse strawberry production studies at UNL (Paparozzi, et al, 2011, 2012 a, b, 2013). The concept of a Cap Mat system is to establish a capillary column of water or nutrient flow from a moist fabric, mounted on a bench top and the plant root system contained in a pot. Consequently, plant leaves are kept dry, while the whole plant growth system is driven by photosynthesis and transpiration.

\section{Soft Computing Modeling}

Mathematical modeling and dry matter prediction of greenhouse crop yields have typically relied on formulas, derived statistically from data from plant growth and development experiments. However, plants are a very complex physiological and biochemical systems. Biochemical-thermodynamic, mathematical plant growth models have not been successful due to lack of knowledge of plant growth mechanisms and uncertain conditions. Quantification of growth becomes even more difficult when considering genetic variations in plant cultivars. Plant growth models also become unreliable due to unknown soil and environmental conditions. However, certain climatic and soil conditions can be reasonably controlled within a greenhouse. This leaves us with the primary uncertainty and ambiguity of the plant system, itself. Add to this is the expense and space restrictions of a small greenhouse for experimental research designs.

Considered a topic of soft computing, Zadeh $(1975,1978)$ presented a different type of mathematical modeling that had evolved in eastern countries. He proposed a mathematical Fuzzy Set Theory (FST) for dealing with uncertain, ambiguous, and vague problems. These include those problems with too little or a lack of pertinent experimental data, to support mathematical kinetic growth models, making subsequent conclusions or consequences controversial. Fuzzy logic models are derived using FST, unlike crisp mathematical logic, which is derived from well-known symbolic set theory. The truth of any FST statement or its inference is a matter of degree, given by linguistic membership functions. Examples are: how cold is the outside air; how high should one set the heat on a thermostat; or how large is a green plant? The degree to which a fuzzy statement is true or false is denoted by a numerical value; 0 = "absolutely false", 0.5 = "maximum fuzziness or totally unclear", and 1 = "completely true". 
This is called "the degree of membership for a fuzzy set, usually denoted as linguistic variables". Fuzzy inference systems rely on membership functions and simple logical implications: "and", "or", and "not". This perhaps is the basis of human deductive reasoning (fuzzy set theory, Cartesian products, implication strength, and composition; Ross, 2016). Fuzzy modeling does not preclude statistical or probabilistic thinking, as goodness of fit and validation of such models still remains important for assessing their usefulness for plant growth systems.

Fuzzy logic modeling has been applied to greenhouses and crop growth studies (Kurata and Eguchi, 1990, Center and Verma, 1997, Al-Faraj, et. al, 2000, Rudnick, et. al, 2015, as examples). Among the various combinations of methodologies of soft computing, the one that has the highest visibility at this juncture is that of fuzzy logic combined with a neuro learning techniques (sometimes called artificial intelligence). Combined with fuzzy logic, such systems play a particularly important role in the induction of rules for useful knowledge, given numerical data or even qualitative observations. Roger Jang (1993) developed an effective method for this purpose called ANFIS (Adaptive Neuro-Fuzzy Inference System), which can be used to develop nonlinear models of arbitrary complexity. ANFIS is a special function found in the Fuzzy Logic Toolbox of the mathematical computing software MATLAB® (Mathworks, Inc., Natick, MA.). ANFIS generates fuzzy logic rules, driven by data for the deduction or inference process.

When considering a fuzzy logic, rule-based model (e.g. driven by basil plant data), the number of antecedents or inputs can influence the logic or in this case the number of rules. The growth of basil in an environmentally controlled greenhouse is based on the amount of time for the plant to achieve its maximum vegetative growth, water and fertilizer treatments, and cultivar type. Clustering is used to group data elements with apparent similarities, prior to ANFIS. Clustering of the data is intended to identify the sets of categories to be distinguished as fuzzy membership functions (MF). MF as fuzzy sets are represented as linguistic variables. Because of inherent ambiguity of these systems, linguistic variables will overlap to accommodate the uncertainties or ambiguities within the data.

MATLAB has three clustering functions that can be used with ANFIS to design a potential model or a fuzzy inference system (FIS). GENFIS1 is a grid partitioning method, which tends to develop as many clusters as there are apparent similarities. GENFIS2 subtractive clustering, is a fast, one-pass algorithm for estimating the number of clusters and their cluster centers, for a given set of data. GENFIS3 uses Fuzzy C-Means (FCM) as a third data clustering alternative. FCM was introduced by Bezdek (1981) as an improvement to simpler clustering methods. With FCM, each data point belongs to a cluster to some degree that is specified by a membership grade. Another clustering method that has shown good results in pattern recognition is the Gustafson- Kessel (GK) cluster method (Gustafson and Kessel, 1979).

\section{Study Objectives ${ }^{1}$}

1. To study the behavior of the greenhouse Cap Mat II bench system, relative to cultivar, water, and nutrients, for winter-time greenhouse basil production.

2. To investigate the use of fuzzy logic as a tool for predicting basil crop production and classification of cultivars.

\section{Methods and Procedures}

${ }^{1}$ This research was funded in part by small grants from Horticulture Specialty Block Grant Program, and the USDA/ NIFA Multistate project NE-1335 “Resource Management in Commercial Greenhouse Production”. The mention of specific trade names is for reference only and not to the exclusion of other commercial products. Special thanks and remembrance is given to Mr. Gary Debergæ, whose innovations contributing to the Capillary Mat system made this study possible. Special thanks are also given to Ms. Tiffany Riffle and Mr., Alex Monette, undergraduate research assistants. 
To accomplish these objectives, studies were performed using a small and existing, double polyethylene Quonset, commercial-style, production greenhouse (ENT-3, located on the University of Nebraska East Campus. The dimensions of ENT-3 were 6 × $25.5 \times 3 \mathrm{~m}$ at the peak (20 x 84 × $10 \mathrm{ft}$.). This house featured a simple, clear-span construction with hand-constructed benches. A capillary mat system (Cap Mat IITM, Phytotronics, Inc., Earth City, MO USA) was used on the benches with an automatic watering/fertigation system. Basil crops were grown on two separate 1.8 x 6 m (6 x 20 ft.) north-south benches, shown in Figure 1.

White reflective plastic mulch was applied over the Cap Mats for improved immersion of plants with sunlight or photosynthetically-active-radiation (PAR). The actual amount of short wave energy intercepted (PAR) by plants was related to canopy architecture and plant population. Ideally, a plant fully bathed in PAR (top and bottom leaves) should be a productive plant (Meyer, et al 2012).

Each bench had its own natural gas furnace and fan tube (replaced and upgraded in summer of 2016). The fantube distribution systems were located under each of the two benches to distribute bottom heat. The heating design included a single thermostat sensor at bench level at the middle of the house, which was significant for maintaining media temperatures at desired levels. ENT-3 was equipped with low-cost instruments and sensors to continually monitor air and media temperatures, humidity, light quantity (PAR), water and fertilizer utilization, as well as heating and cooling operations. Furnace and ventilation events in ENT-3 were automatically controlled by a Groton II system (ACME Engineering and Manufacturing, Inc., Muskogee, OK).

\section{Production Activities}

Several years of basil studies were undertaken. This manuscript will only report results from two studies, 2015 and fall 2016. The initial selection study of basil (Ocimum spp.) was performed in ENT-3 in late fall 2014 through spring 2015. Seeds were purchased from Johnny's Selected Seeds, Winslow, ME, and included eight basil (Ocimum basilicum) cultivars, as shown in Table 1. The 2015 study provided 136 data points for the eight cultivars that included harvest dates, dry weights for leaf, stem, and flowers. The 2016 study used only 34 data points that included just total plant weight per pot for two highlighted cultivars: Eleonora and Lime, with corresponding sensor data, described below.

Table 1. Basil Cultivars (in bold) Studied and Reported in this paper.

\begin{tabular}{|c|c|c|}
\hline \multirow{2}{*}{ Identifier Number } & \multicolumn{2}{|c|}{ Cultivar Name } \\
\cline { 2 - 3 } & 2015 & Fall 2016 \\
\hline 1 & 'Nufar' & 'Amethyst' 'Sweet Thai' \\
\hline 2 & 'Italian Large' 'Dolly' \\
\hline 3 & 'Mrs. Burns' Lemon' & 'Cinnamon' \\
\hline 4 & 'Aroma 2' 'Eleonora' (1) \\
\hline 5 & 'Dolly' & 'Lime' (2) \\
\hline 6 & 'Holy' & 'Napoletano' \\
\hline 7 & 'Spicy Globe' & 'Genovese' \\
\hline 8 & &
\end{tabular}

The basil plants consisted of popular field cultivars. Among them, 'Italian Large Leaf', 'Nufar', ‘Aroma 2', 'Dolly' and 'Genovese' are classic sweet pesto basil type, 'Nufar' and 'Aroma 2' are Fusarium-resistant; 'Mrs. Burns' Lemon' is a specialty basil with a citrus aroma; 'Spicy Globe’, also a specialty basil, has a spicy aroma and is commonly used as an ornamental; 'Holy' basil has unique aroma, medicinal qualities and it is different from all the other cultivars. Seeds of all the cultivars except Genovese (October 24th) were sown in October 3rd, 2014. Five weeks later, the seedlings were transplanted into 6-inch pots, filled with a soilless mix consisting of sphagnum moss peat, vermiculite, and perlite (1:1:1) and one of 3 rates of slow release fertilizer $\left(0,6\right.$ or 9 g per pot of Osmocote ${ }^{\mathrm{TM}}$ 
Bloom 12-7-18). Plants in each pot were thinned to three plants after four weeks. The production timelines are shown in Figures 2 and 3.

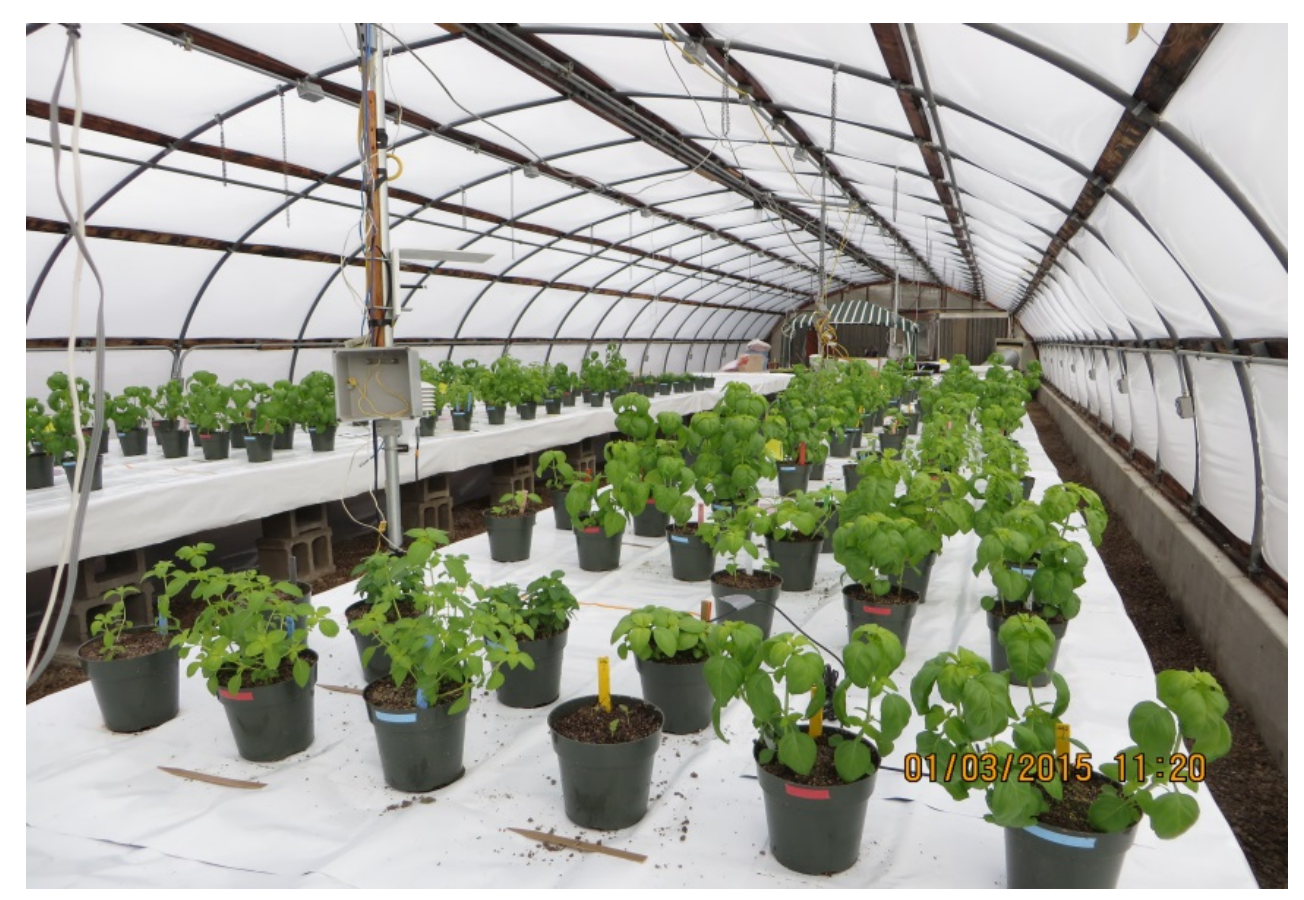

Figure 1. Decagon GS3 ${ }^{\mathrm{TM}}$ instrumented Cap Mat II benches for basil production studies.

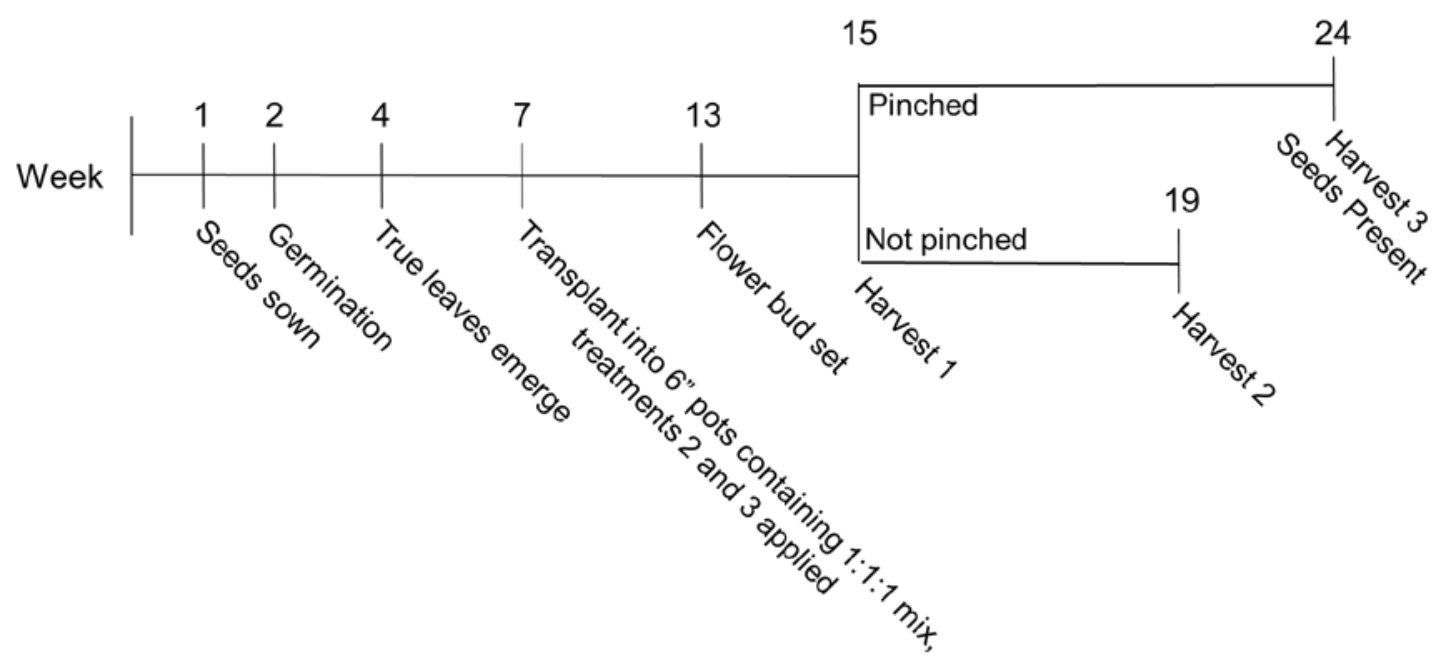

Figure 2. Production time line for all cultivars of Ocimum basilicum. 


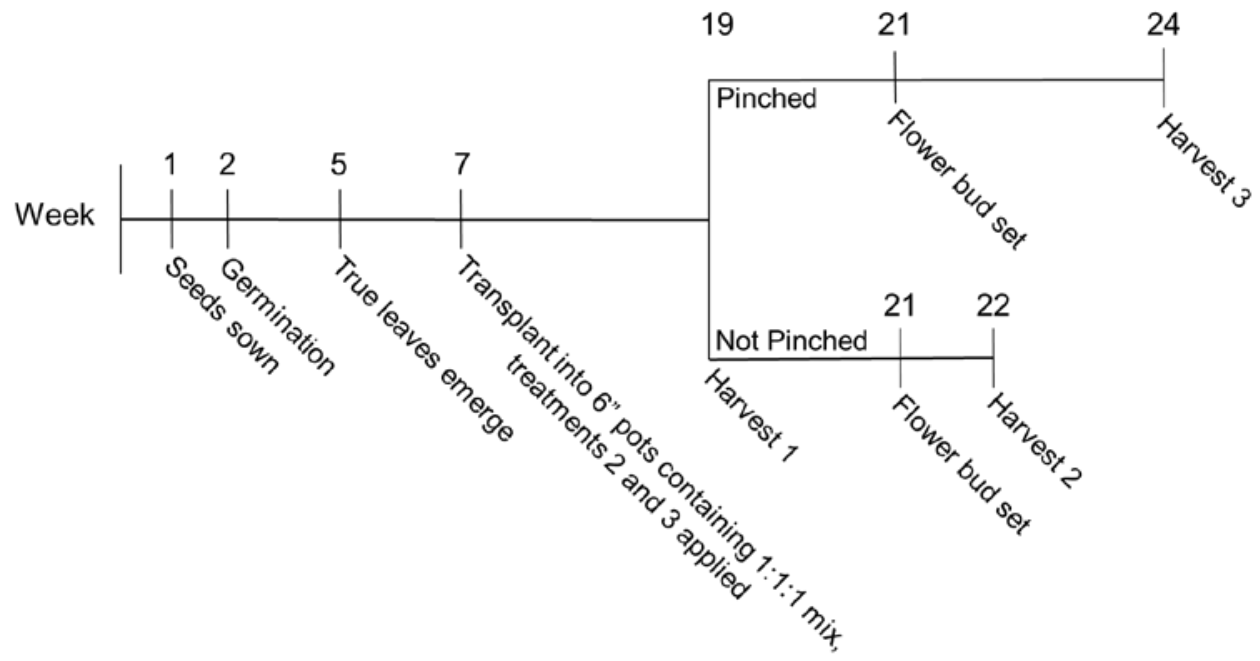

Figure 3. Production time line is for Ocimum sanctum, cv. Holy.

\section{$\underline{\text { Fertigation and Soil Sensors }}$}

The 2015 and fall 2016 experiments were approximately three months long. This was based on a commercial basil grower's timeline for turnover of product for fresh market. The capillary mat system was used to water and provide fertigation (100 ppm N 20-10-20) for the studies. Liquid water and fertilizer was prepared in a supply tank and then used to moisten the Cap Mats, on a selected time event schedule using a timer clock. The benches were also covered with a single layer of 6 mil, black polyethylene as an initial water and vapor barrier to the floor. Cap Mat (water absorptive) fabric was installed on top of the black plastic. Four mil white, polyethylene, top/black bottom (Panda plastic) covered the absorptive fabric, in which holes were cut for each pot. A special jig device was used to space and install holes to allow individual pots to access the wet fabric through the white polyethylene cover (the reflective mulch). The holes were spaced to allow working areas between pots.

The Panda plastic cover also served as a vapor barrier to reduce evaporation of moisture to the air. Standard 6" pots were set onto each mulch hole of the fabric. The Cap Mat absorptive fabric was then wetted using twin wall "seep hose" tubing installed between the white/black polyethylene and the fabric. Pots were initially watered from the top to facilitate the growth of transplanted seedlings. In time, roots grew at the bottom of the pots and through the reflective mulch holes into the mat. Once rooting was established into mat, pots could not be removed or disturbed to avoid breaking the capillary process.

GS3® soil media sensors (Decagon Devices, Inc. Pullman, WA) were installed during transplanting directly to the media within selected pots and basil cultivars. The GS3 sensors measured volumetric water content, media temperature, and electrical conductivity. A commercial soilless mix consisting of peat moss (50\%), pine bark and perlite with dolomite and started nutrients was used for each pot. A soil sample was sent to Decagon for GS3 calibration. A slow release fertilizer was used along with starter nutrients. A total of eight soil sensors (four per bench) were installed. Daily watering events were adjusted during the season according to crop and environmental conditions to minimize night time humidity levels and to reduce plant disease and pest pressure. The goals were to sufficiently water and fertilize each basil pot, across each bench, maintaining a 50-60\% volumetric water content set point.

Sensors also included PAR, air temperature, and relative humidity similar to those reported by Meyer, et.al. (2014) and Burnett, et. al. (2012). Sensor readings were recorded every 10-minutes, using a Campbell CR1000 data logger (Campbell Scientific, Logan UT) and downloaded weekly for review, plotting, and analysis of the conditions in the greenhouse. The acquired aerial environmental data was not an outcome of these studies, but rather to ascertain the level of greenhouse environmental control was attained. If Cap Mat and greenhouse temperatures and 
humidity control were good, then the focus would be on simplifying the crop cultivar study and subsequent modeling itself. However, plant lighting from the sun varied naturally during the study periods. There was no artificial lighting.

\section{Fuzzy Inference and Classification Modeling}

Crop experiment data from 2015 was organized into columns of antecedents (inputs) and a consequence (output), using Microsoft Excel. A special MATLAB® (v. R2016a) script with UI Controls (user friendly interface) was written to read the data, execute Fuzzy Toolbox ANFIS functions, and the Statistics Toolbox validation functions. The GENFIS2 clustering method was used, based on previous studies, as it produced smaller sets of rules then GENFIS1 or GENFIS3. Figure 4a shows a typical Takagi Sugeno fuzzy inference system (Takagi and Sugeno, 1985). Fuzzy classification is sometimes best based on the Mamdani fuzzy inference system (Mamdani, et al, 1975). Figure 4b shows that class membership functions can be developed based on crisp frequencies of Sugeno output values.

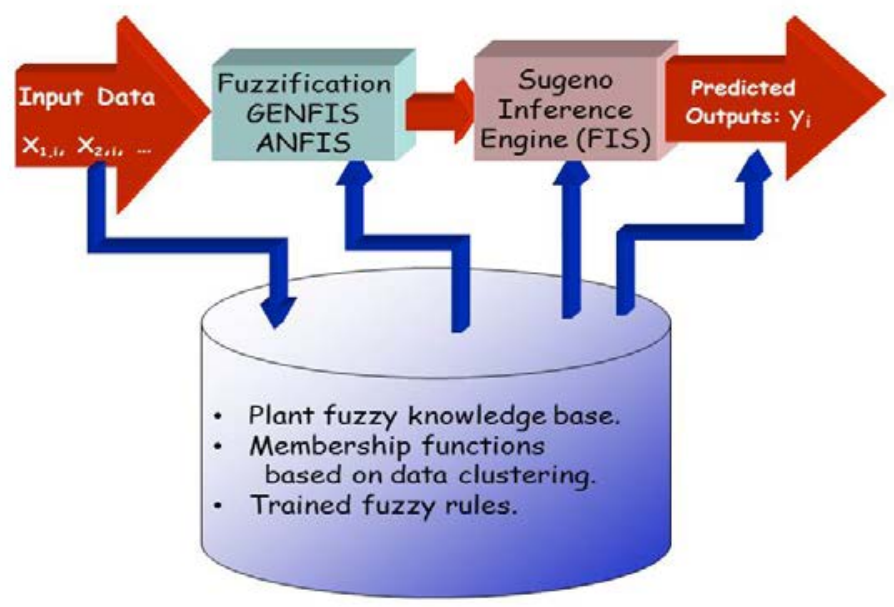

(a)

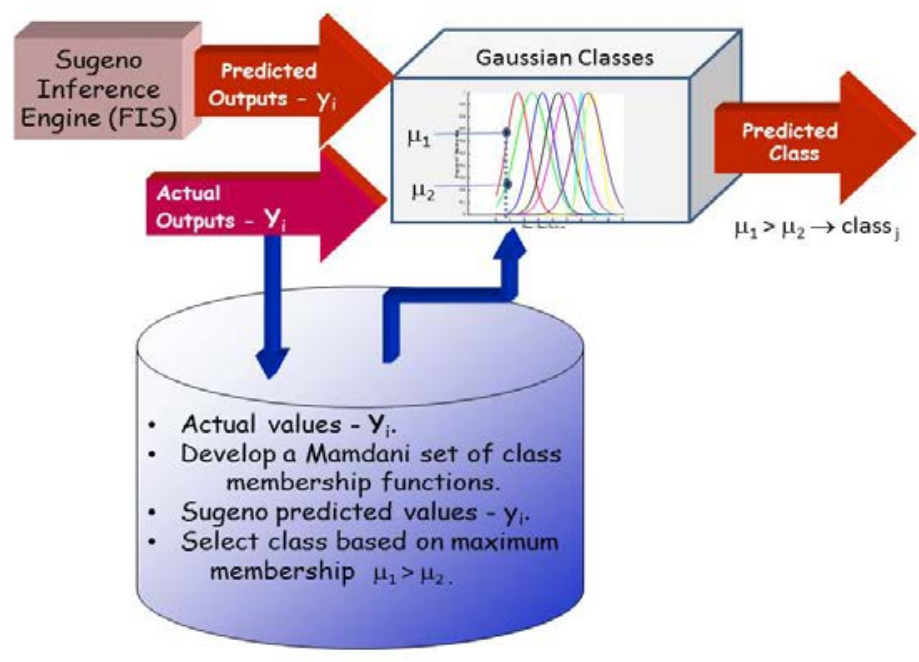

(b)

Figure 4. Fuzzy logic inference production and cultivar class model for basil production: (a) GENFIS2- ANFIS Sugeno Model, (b) Mamdani class model. 
Once a Sugeno FIS was initially prototyped, it was then subjected to a back propagation neural network system (ANFIS) to train the rules (maximum-minimum implication) using the experimental antecedent and consequence data at hand. An internal validation process was used to divide the entire data set into random test and validation sets. There are a number of procedures in MATLAB to accomplish this. Internal validation, unlike external validation relies on similarities that may exist among the data elements of the original set. MATLAB function used is given as:

$$
\text { [TRAIN,TEST] }=\text { crossvalind }(\text { 'HoldOut', } r, P)
$$

Equation 1 returns logical index vectors for internal cross-validation of $\mathrm{r}$ observations by randomly selecting $\mathrm{P} * \mathrm{~N}$ (approximately) observations to hold out for the evaluation set. P must be a scalar between 0 and 1 . P defaults to 0.5 when omitted, corresponding to holding $50 \%$ out. Using holdout cross-validation within the testing loop is similar to K-fold, cross-validation, one time outside the loop, except that non-disjointed subsets are assigned to each evaluation. Other MATLAB internal validation methods are available such as: 'LeaveMOut' or 'Resubstitution'.

ANFIS models are essentially Takagi and Sugeno inference types, which means that consequence or output results are calculated as non-integral prediction numbers, even though the training consequences maybe integral. However, the prediction numbers are also uncertain. To make consequence numbers more useful, classes or levels of output (deductive consequence) could be proposed (e.g. little growth, some growth, large growth, very high growth, etc.). In this case, the implication discussion changes to a Mamdani inference. Classes could also be cultivar names, based on plant taxonomy features or the measured dry matter of the plant parts for a cultivar. Thus, if the consequence is an integral class or in this case a cultivar number, a Sugeno FIS may not be the best choice. Therefore, a special set of MATLAB scripts was written to convert the Sugeno outputs to classes of Gaussian membership functions, based on means and standard deviations. The MATLAB fuzzy logic toolbox gaussmf function was used to create these membership functions for each class, given as:

$$
\mathrm{y}=\operatorname{gaussmf}(\mathrm{x},[\operatorname{sigma}(\mathrm{i}) \mathrm{xmean}(\mathrm{i})]) \text {; }
$$

where: $\mathrm{x}=$ the partial class value provided by ANFIS.

$\mathrm{i}=$ the cultivar class identifier (Table 1 ).

sigma $(i)=$ standard deviation for class $i$. xmean(i) $=$ mean value for class $i$.

and: $\quad y=$ the degree of membership.

Cultivar class selection was based on Zadeh's principle of maximum membership (Ross, 2016). Thus, predicted x values would have to be tested through overlapping class membership functions from Equation 2, to find the maximum degree of membership and its associated class identifier for assignment at the correct class. The only requirement is that there are a sufficient number of consequence data points from ANFIS for the subsequent calculations. Therefore, cultivars classifications were used also tested against dry weights of basil plant parts for 2015 and total weights for 2016.

1

\section{Results and Discussion}

Basil production at harvest is shown in Figures 5 and 6. One can observe that canopies were lush. The 2015 data included the cultivar, fertilizer treatment, growth period, dry weights for stems, leaves, and flowers. The fall 2016 had only total plant dry weights, cultivar, fertilizer treatment, but no breakdown on leaves, stems, or flowers.

\section{Production Performance}

Table 2 provides a summary of average dry matter total, leaf, stem, and flower weights and standard deviations for eight basil cultivars grown in 2015. Harvest was carried out from 5 -8 days. The largest plants were Mrs. Burns Lemon, Dolly, and Aroma 2 at: $83.98 \pm 56.63,54.68 \pm 26.67$, and $53.77 \pm 46.86$ grams per plant, respectively. The 
cultivars Holly and Spicy Globe were very small at: $3.63 \pm 3.69$ and $15.66 \pm 13.41$ grams per plant, respectively. The actual data values were subjected to a GENFIS2 - ANFIS modeling test, as discussed later.

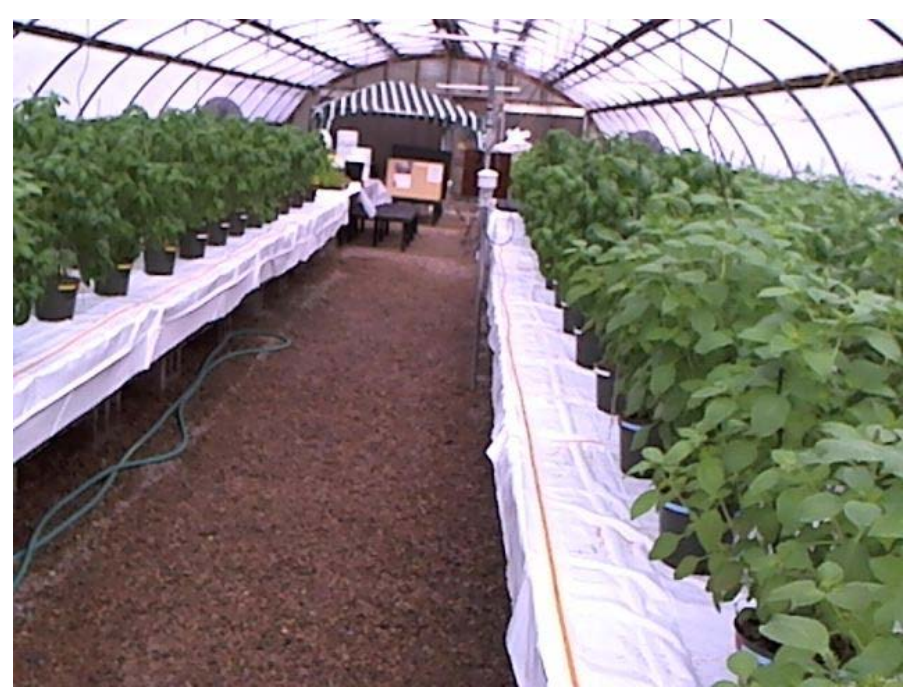

Figure 5. Webcam image of a greenhouse basil crop, grown on Cap Mat II and ready for harvest in 2016.

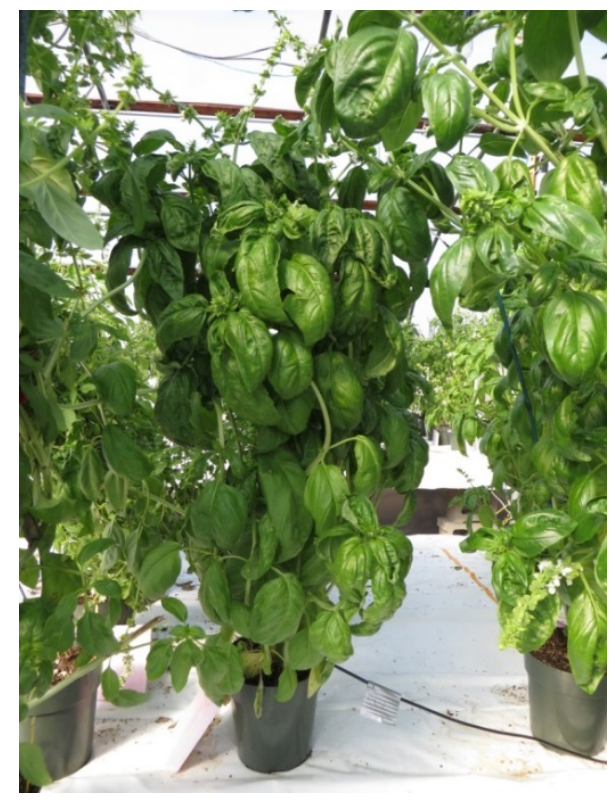

Figure 6. Close up of a mature basil plant in 2015.

Table 2. Summary of Plant Dry Matter - 2015 Basil Cultivars.

\begin{tabular}{|c|l|c|c|c|c|c|}
\hline $\begin{array}{c}\text { Identifier } \\
\text { Number }\end{array}$ & Cultivar Name & $\begin{array}{c}\text { Leaf Weight } \\
(\mathrm{g})\end{array}$ & $\begin{array}{c}\text { Stem Weight } \\
(\mathrm{g})\end{array}$ & $\begin{array}{c}\text { Flower } \\
\text { Weight } \\
(\mathrm{g})\end{array}$ & $\begin{array}{c}\text { Plant Weight } \\
(\mathrm{g})\end{array}$ & $\begin{array}{c}\text { Harvest } \\
\text { Day } \\
(\mathrm{DOY})\end{array}$ \\
\hline 1 & 'Nufar' & $19.57 \pm 16.28$ & $23.09 \pm 21.64$ & $1.53 \pm 2.20$ & $44.17 \pm 39.79$ & 57 \\
\hline 2 & 'Italian Large' & $23.84 \pm 14.35$ & $19.87 \pm 11.60$ & $3.30 \pm 2.91$ & $46.96 \pm 28.13$ & 54 \\
\hline 3 & $\begin{array}{l}\text { 'Mrs. Burns' } \\
\text { Lemon' }\end{array}$ & $25.71 \pm 16.12$ & $42.98 \pm 29.96$ & $15.23 \pm 13.82$ & $83.98 \pm 56.63$ & 64 \\
\hline 4 & \begin{tabular}{c} 
'Aroma 2' \\
\hline 5
\end{tabular} & $21.28 \pm 18.15$ & $26.99 \pm 23.10$ & $5.43 \pm 5.97$ & $53.77 \pm 46.86$ & 59 \\
\hline 6 & 'Dolly' & $29.23 \pm 14.32$ & $23.12 \pm 10.79$ & $2.28 \pm 2.02$ & $54.68 \pm 26.67$ & 57 \\
\hline 7 & 'Holy' & $2.50 \pm 2.45$ & $1.10 \pm 1.22$ & $0.07 \pm 0.17$ & $3.63 \pm 3.69$ & 67 \\
\hline 8 & 'Spicy Globe' & $6.46 \pm 6.36$ & $6.94 \pm 5.51$ & $2.22 \pm 2.31$ & $15.66 \pm 13.41$ & 60 \\
\hline
\end{tabular}




\section{Fall 2016 GS3 Sensor and Cap Mat Production Performance}

Greenhouse electronic sensor performance data for fall 2016 are additionally shown in the attached Appendix. These series demonstrate the diurnal behavior of the GS3 and other sensors. The GS3 volumetric water content sensor also shows the solenoid on/off events that occurred daily. Average and standard deviation values for the Decagon GS3 Sensor Data for fall 2016 are shown in Table 3. The fertigation process begins at the manifold at the south end of each bench, with the flow of water and nutrients toward the north end. The control system maintained the volumetric water content around 0.5 (50\%) over the basil growth period in 2016. Pot media temperatures varied slightly relative to the east and west benches at about $1-2{ }^{\circ} \mathrm{C}$, with the west bench being slightly cooler. Electrical conductivities located at the south end of the benches were above $100 \mu$ Siemens/cm and dropped to approximately 20\% downstream in the Cap Mat, as the basil plants apparently utilized the nutrients.

There was more consistency in volumetric water content and media temperature over both benches, than what we had observed during other experiments. Thus, the under the bench heating system kept the media temperatures at a good range level for root growth. Nighttime greenhouse air temperatures were maintain around $20^{\circ} \mathrm{C}$, while daytime air temperatures ranged from 25 to $30^{\circ} \mathrm{C}$, based on whether the sky was cloudy or not. This was probably due to the cooler outside air temperatures, which allowed the heat and fertigation system to operate consistently.

The EC on the west bench changed along the north-south gradient with a higher level at the south end, but decreasing to the north end. The EC on the east bench varied, but was also lower on the north end. In terms of plant dry weight (Table 2a), this variation in EC, did not appear to translate to more growth. On the east bench, plants at the north and south ends were heavier than the ones in the middle of the bench. This occurred, despite similar incoming light levels at the two measured locations (see Appendix). This is probably due to plant-to-plant shading particularly as the plants grew bigger. For the west bench, there was actually more growth, but with less nutrients (EC) present. This makes sense as bigger plants will utilize more water/nutrients than smaller plants. These EC levels however are less than typical commercial recommendations of 1 to $2 \mathrm{mS} / \mathrm{cm}$. Fortunately most literature indicates that basil does not need high fertility levels for good growth and most cultivars grew well under these winter conditions.

The attached Appendix shows figures of sample time series of the sensors used to monitor this greenhouse in 2016. The Appendix (Figures 15 and 16) show the time series of outside air and inside greenhouse air temperatures for fall 2016, respectively. Outside air temperatures were around $25^{\circ} \mathrm{C}$ during the day time (typical fall temperatures) and night time temperatures began to drop below freezing in early November. Appendix (Figures 17 and 18) show the Photosynthetically Active Radiation (PAR) levels in the greenhouse. Daily PAR levels cycle diurnally and maximum levels were approximately 400 to $500 \mu$ moles per $\mathrm{cm}^{2}$ per s, during the early part of the vegetative growth period. The PAR levels tended to decrease, as the photoperiods became shorter and the sun angle decreased, later into the fall.

Figures 19 and 20 show the soil media temperatures and volumetric water contents for GS3 sensor E, respectively. Media temperatures were fairly steady around 19 to $23^{\circ} \mathrm{C}$; except on four occasions when temperatures rose above $25^{\circ} \mathrm{C}$. There appeared to be no correlation with PAR levels at those times, so the reason for this is unknown. Volumetric water content ranged between 0.5 and 0.6 during the early part of the growing period. Pots became slightly drier as the plants grew larger.

Figure 21 shows a typical time series for electrical conductivity for GS3 sensor E. Other pot sensor time series are available, but not shown. As with previous studies not reported here, there was a modest rise in EC values, as pots were never flushed with pure water from the top, as the crop was established. 
Table 3. Average Decagon GS3 sensor data and harvest weights for the study period: October 24 - November 29, 2016. The basil cultivars were 'Eleonora' a pesto basil and 'Lime', a specialty basil. There were three plants per pot, except one pot had only two plants. All plants received the same fertilizer treatment.

\begin{tabular}{|c|c|c|c|c|c|c|c|}
\hline $\begin{array}{c}\text { Volumetric } \\
\text { Water } \\
\text { Content } \\
\text { (fraction) }\end{array}$ & $\begin{array}{l}\text { Pot Media } \\
\text { Temperature } \\
{ }^{\circ} \mathrm{C}\end{array}$ & $\begin{array}{c}\text { Electrical } \\
\text { Conductivity } \\
\mu \text { Siemens } / \mathrm{cm}\end{array}$ & $\begin{array}{l}\text { Harvest Plant } \\
\text { dry weight }(\mathrm{g})\end{array}$ & $\begin{array}{l}\text { Volumetric } \\
\text { Water Content } \\
\text { (fraction) }\end{array}$ & $\begin{array}{c}\text { Pot Media } \\
\text { Temperature } \\
{ }^{\circ} \mathrm{C}\end{array}$ & $\begin{array}{c}\text { Electrical } \\
\text { Conductivity } \\
\mu \text { Siemens } / \mathrm{cm}\end{array}$ & $\begin{array}{l}\text { Harvest Plant } \\
\text { dry weight (g) }\end{array}$ \\
\hline \multicolumn{8}{|c|}{ North Bench End } \\
\hline \multicolumn{4}{|c|}{ West Bench } & \multicolumn{4}{|c|}{ East Bench } \\
\hline \multicolumn{4}{|c|}{ Sensor GS3 -H - 'Lime' } & \multicolumn{4}{|c|}{ Sensor GS3 -D - 'Eleonora' } \\
\hline $0.51 \pm 0.05$ & $20.56 \pm 3.06$ & $97.87 \pm 9.46$ & 54.68 & $0.50 \pm 0.02$ & $23.55 \pm 2.56$ & $120.66 \pm 16.35$ & 51.34 \\
\hline \multicolumn{4}{|c|}{ Sensor GS3 -G - 'Lime' } & \multicolumn{4}{|c|}{ Sensor GS3 -C - 'Lime' } \\
\hline & & & & & & & \\
\hline$n / a^{2}$ & $20.83 \pm 1.66$ & $88.78 \pm 8.21$ & 43.07 & $14.36 \pm 3.08$ & $21.46+2.55$ & $133.12 \pm 32.47$ & 53.38 \\
\hline \multicolumn{4}{|c|}{ Sensor GS3 -F - 'Eleonora' } & \multicolumn{4}{|c|}{ Sensor GS3 -B - 'Eleonora' } \\
\hline $0.50+0.04$ & $20.90+3.69$ & $107.48+12.22$ & 44.81 & $0.54+0.03$ & $23.80 \pm 3.17$ & $165.57+28.95$ & 61.17 \\
\hline & & & & & & & \\
\hline \multicolumn{4}{|c|}{ Sensor GS3 -E - 'Eleonora' } & \multicolumn{4}{|c|}{ Sensor GS3 -A - 'Lime' } \\
\hline $0.50+0.03$ & $20.27+1.64$ & $120.60+20.15$ & 56.3 & $0.56 \pm 0.03$ & $23.39+2.82$ & $147.50+34.34$ & 54.04 \\
\hline & & & & & & & \\
\hline \multicolumn{8}{|c|}{ South Bench End } \\
\hline
\end{tabular}

\footnotetext{
${ }^{2}$ The GS3 VWC G sensor failed, but unit could not be replaced without damaging the roots into the Cap Mat.
} 


\section{Fuzzy Basil Model Performance}

Apparent basil growth based on total dry matter was subject to a MATLAB ANFIS study. GENFIS2 (subtractive clustering) produced three antecedent Gaussian membership functions, shown in Figure 7. The consequence is dry matter of the plant. FCM (GENFIS3) did not show good results, probably due to limitations in the clustering properties. GENFIS1 generated too many rules $(>100)$ as overfitting of the data occurred. 2015 basil cultivar Studies showed that subtractive clustering of the data along with training of rules (radius of influence $=0.4)^{3}$ can result in good correlation $\left(\mathrm{R}^{2}=0.95\right)$ with 26 rules between actual and predicted growth in total dry matter, as shown in Figure 8. Figure 9 shows the results of internal validation, where the data was divided between training and testing sets. Training and internal validation results are very good.

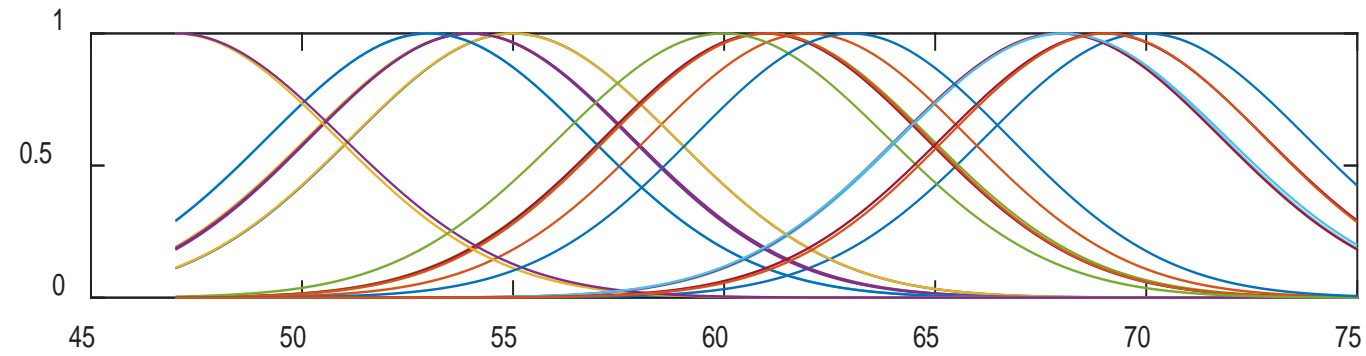

Membership Functions (GENFIS2) Input Variable-1
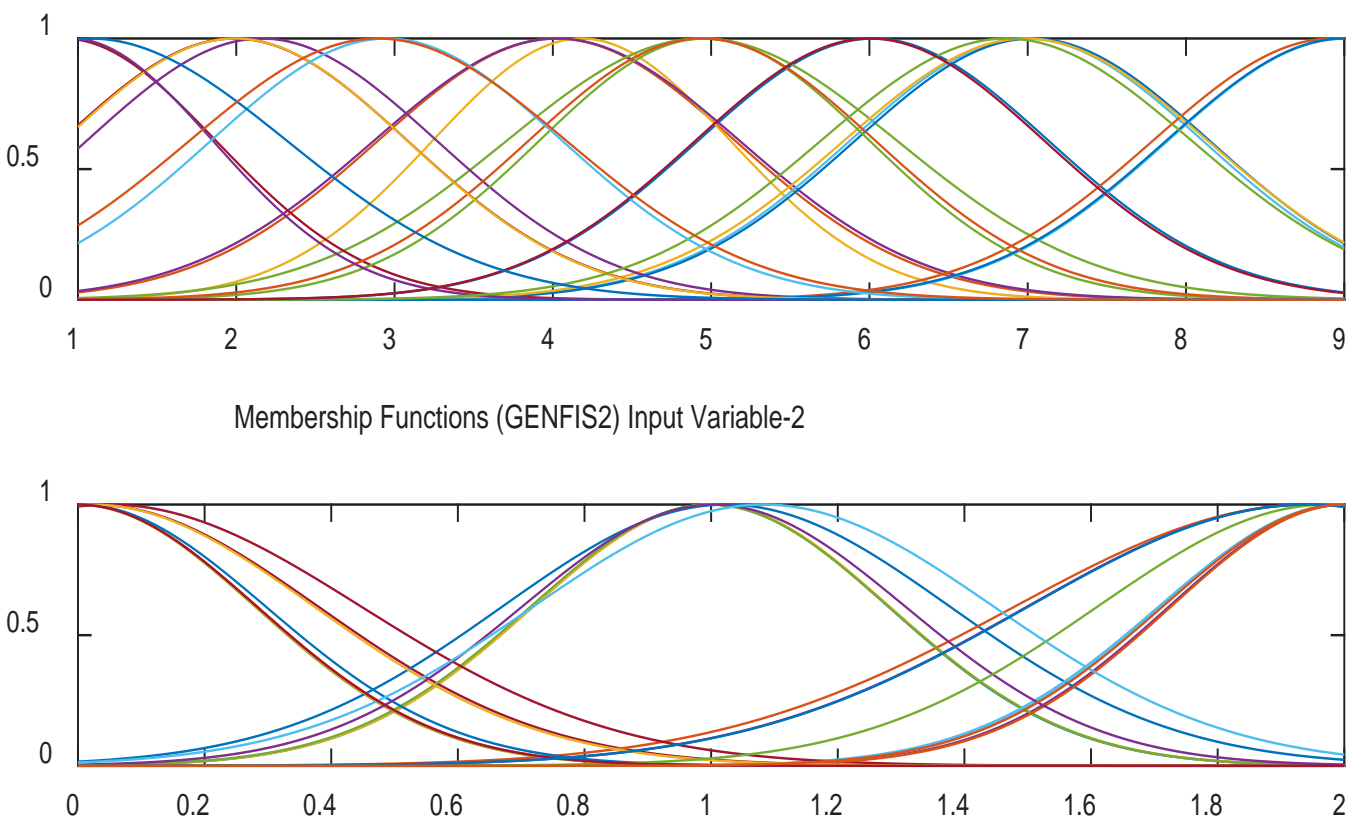

Membership Functions (GENFIS2) Input Variable-3

Figure 7. MATLAB GENFIS2 antecedent membership functions for base Fuzzy Logic Model (2015 Data). (Variables: 1-Harvest day (DOY), 2- Eight Basil cultivars, and 3 - Three fertilizer treatment levels).

${ }^{3}$ GENFIS2 Radius of influence is a vector that specifies a cluster center's range of influence in each of the data dimensions, assuming the data falls within a unit hyperbox. 


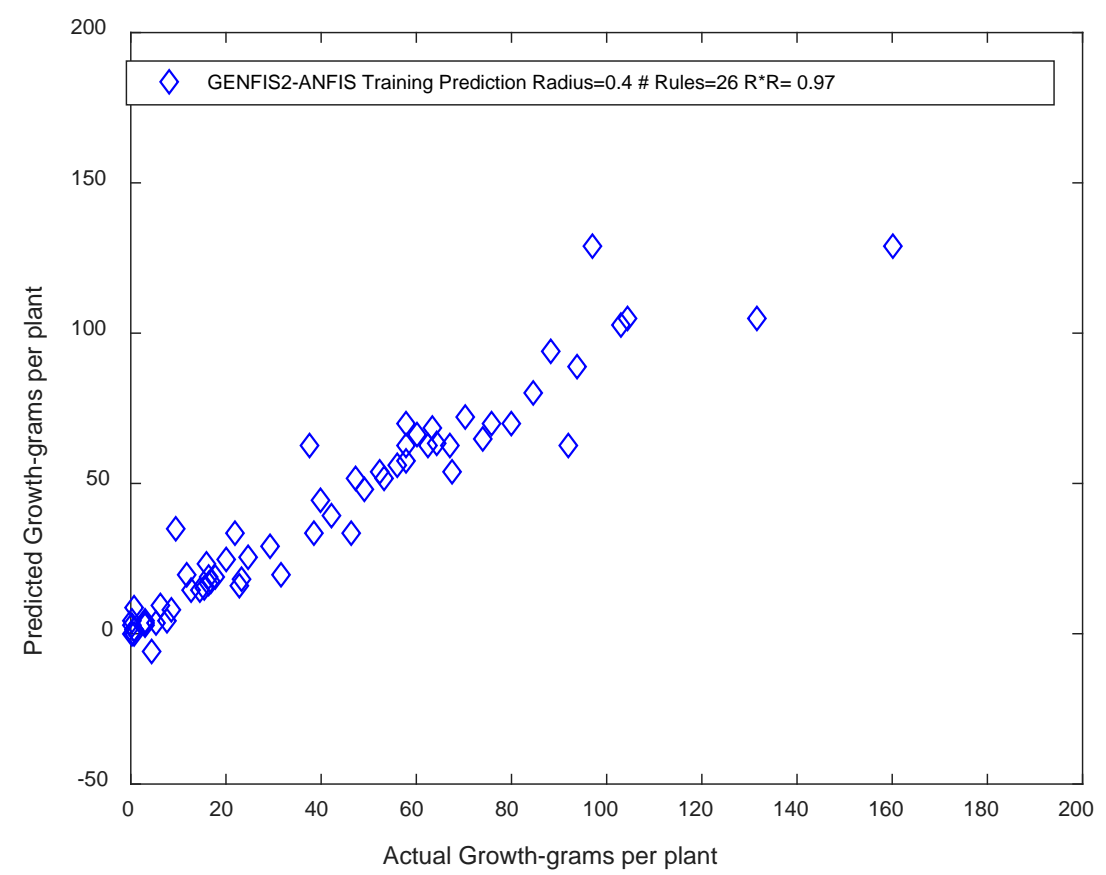

Figure 8. ANFIS (Adaptive Neuro-Fuzzy Inference System) training results using Subtractive Clustering and a Radius of Influence of 0.4 (2015 data).

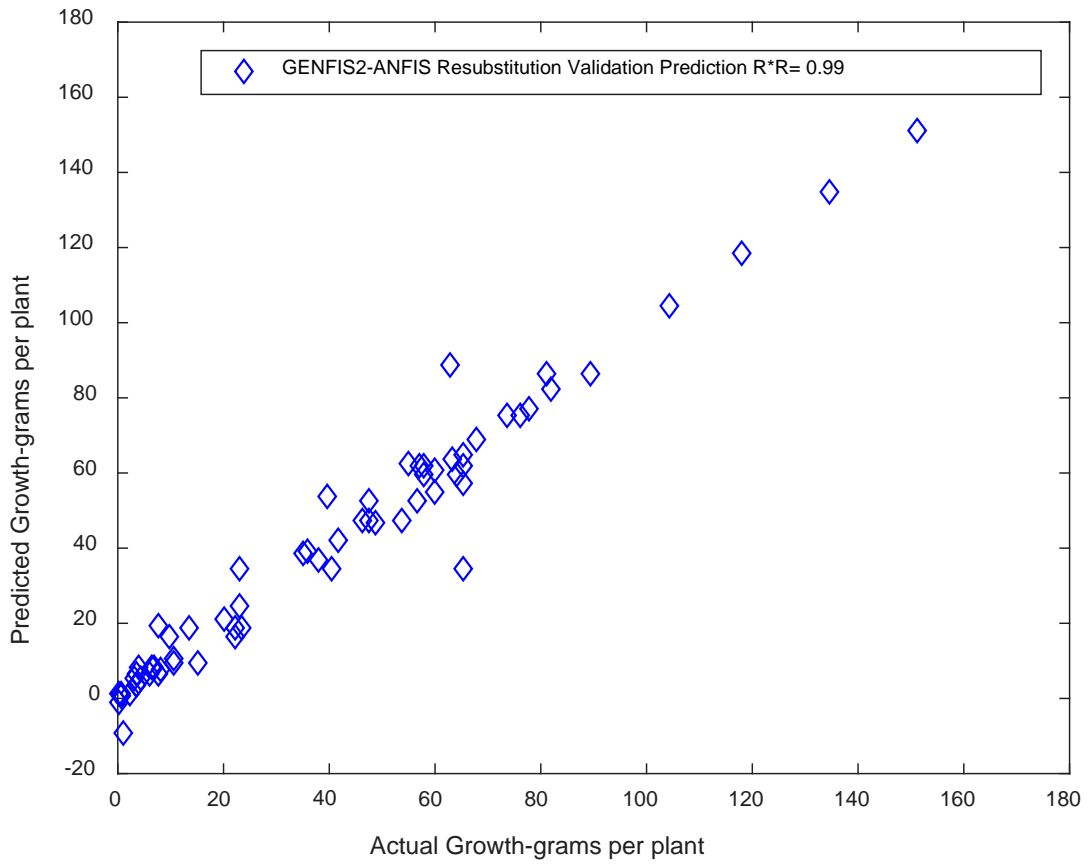

Figure 9. ANFIS FIS and Internal Resubstitution validation results from Figure 8. (2015 Data). 
The fuzzy classification approach to basil modeling may be useful. The basic approach considers the question: is there a possible classification of specific cultivar with the production weight? Were there enough similarities and dissimilarities of the basil plants, based on measured dry matter of the leaves, stems, and flowers to classify cultivars that were available in the 2015 study, as shown in Figure 10? However, the Sugeno cultivar classification results overlap in the vertical sense, making it difficult to determine the correct classification rates.

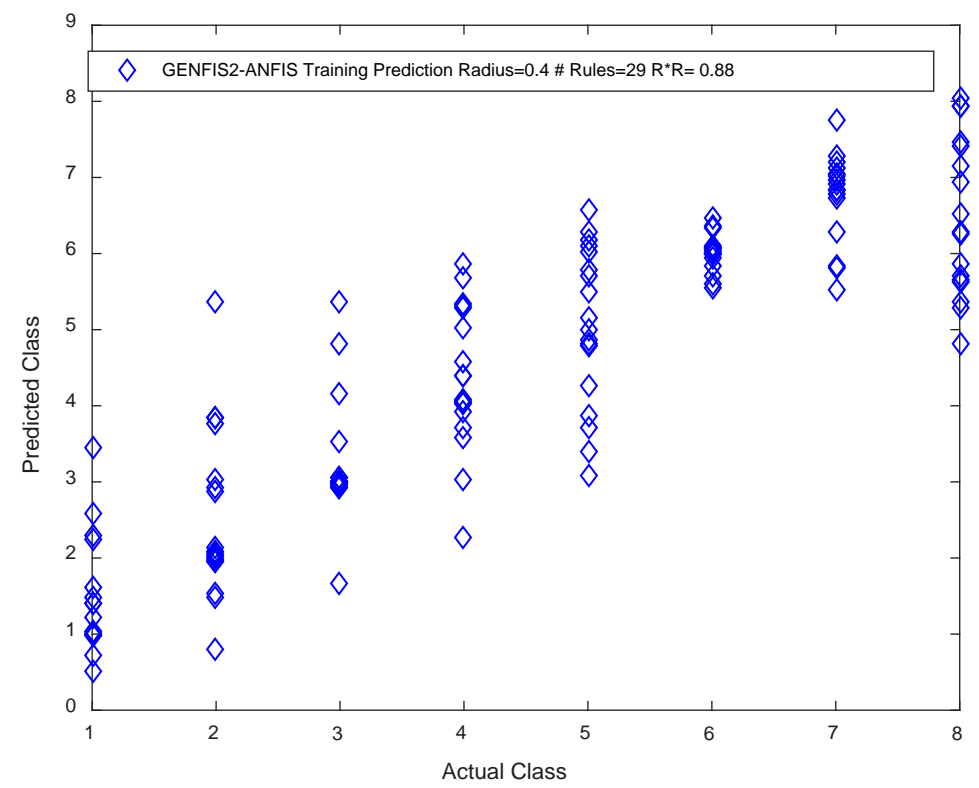

Figure 10. ANFIS Trained cultivar classification with Resubstitution internal validation for eight tested Basil cultivars (2015), using identification numbers as shown in Table 1.

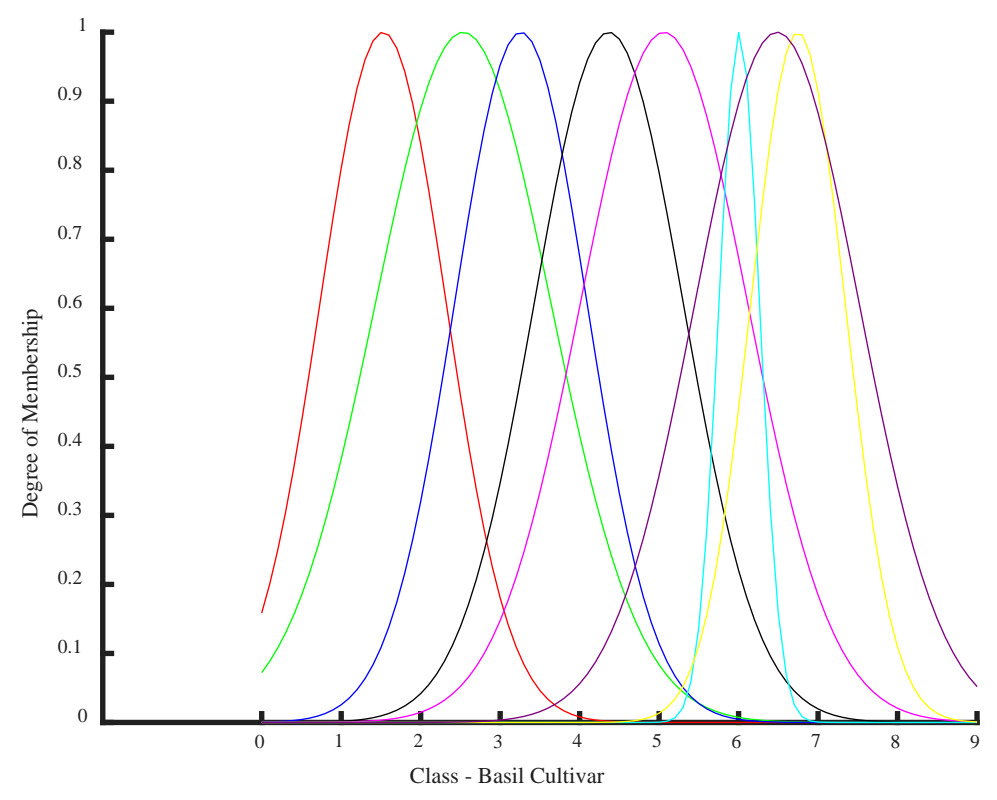

Figure 11. Predicted 2015 cultivar classes as a set of Gaussian Mamdani membership functions, based on training FIS and subsequent validation data (Figure 10). Each cultivar class has a different color, but numbered according to Table 1. 
Figure 10 shows a classification performance for cultivars using ANFIS and GENFIS2 subtractive clustering and 29 rules with an $\mathrm{R}^{2}$ of 0.88 . However, high correlations can be misinterpreted when using non-integer Sugeno class results. (The same result can be shown when using canonical discriminant analysis).

However, Zadeh's principle of maximum membership can be used where fuzzy membership functions for the consequence can be developed from ANFIS Sugeno output data. If enough output data is available, one can fit a Gaussian distribution of results for each class, based on class means and standard deviation. Figure 11 shows the consequence then as a set of Gaussian membership functions. Each function is color coded to represent the different cultivar classes. These too overlap, which is okay. The logical deduction or implication is that given a non-integral class prediction, the correct class to be selected is the one with highest membership value.

Table 4 shows the 2015 confusion matrix (MATLAB function confusionmat) for displaying correct and incorrect class assignments. Correct assignments follow the diagonal of the matrix. Individual class percent assignment accuracies ranged from 73.3 (class 1 - cultivar 'Nufar') to 38.8 percent (class 5 - cultivar 'Dolly'). Cultivar class 'Genovese' was correctly identified at 58.8percent. The table would suggest that with these many cultivars with too much dissimilarity. Additional plant physiological and/or phenotyping information would be needed for better identification of cultivars.

Table 4. Confusion matrix: Classification rates for eight Basil Cultivars (2015 Data) - 54.1 \% Overall Accuracy.

\begin{tabular}{|c|c|c|c|c|c|c|c|c|c|}
\hline & & \multicolumn{8}{|c|}{ Predicted Cultivar Numbers } \\
\hline & & 1 & 2 & 3 & 4 & 5 & 6 & 7 & 8 \\
\hline \multirow{8}{*}{$\begin{array}{c}\text { Actual } \\
\text { Cultivars } \\
\text { Number }\end{array}$} & 1 & 11 & 3 & 1 & 0 & 0 & 0 & 0 & 0 \\
\hline & 2 & 3 & 10 & 2 & 2 & 1 & 0 & 0 & 0 \\
\hline & 3 & 1 & 3 & 10 & 1 & 2 & 0 & 0 & 0 \\
\hline & 4 & 0 & 1 & 3 & 8 & 5 & 1 & 0 & 0 \\
\hline & 5 & 0 & 0 & 3 & 2 & 7 & 1 & 0 & 5 \\
\hline & 6 & 0 & 0 & 0 & 0 & 3 & 9 & 0 & 4 \\
\hline & 7 & 0 & 0 & 0 & 0 & 1 & 0 & 8 & 7 \\
\hline & 8 & 0 & 0 & 0 & 0 & 6 & 0 & 1 & 10 \\
\hline
\end{tabular}

The total plant dry weight per pot, estimated electrical conductivity, and cultivar for each pot, was used for the fall 2016 dry matter data set. There were eight flag measurement pots equipped with Decagon GS3 sensors, resulting in only eight sets of electrical conductivities available for 2016 study. Using these measured EC values from the sensor pots (four pots per two cultivars, shown in Table 3), EC values were then estimated for the other pots by linear interpolation. The EC interpolation equations resulted in good fits $\left(\mathrm{R}^{2}>0.98\right)$. Figures 12 and 13 show Sugeno results from ANFIS training and validation. The 2016 results show excellent correlation.

Using the 2016 data, there was enough Sugeno output data from the ANFIS step and validation to demonstrate Mamdani prediction of the two classes of cultivars Eleonora and Lime ${ }^{4}$. Figure 14 shows the resulting Gaussian functions and the confusion matrix, along with classification rates. As one can observe, the two cultivar classes slightly overlap, as an indication that these are indeed still slightly fuzzy variables for the cultivars. However, using just two cultivars, the classification rates for Eleonora and line were 87.5 and 93.8 percent, as shown respectively by the confusion matrix.

4 MATLAB has the following intrinsic transformation function, but not vice versa: sug_fismat = mam2sug(mam_fismat); 


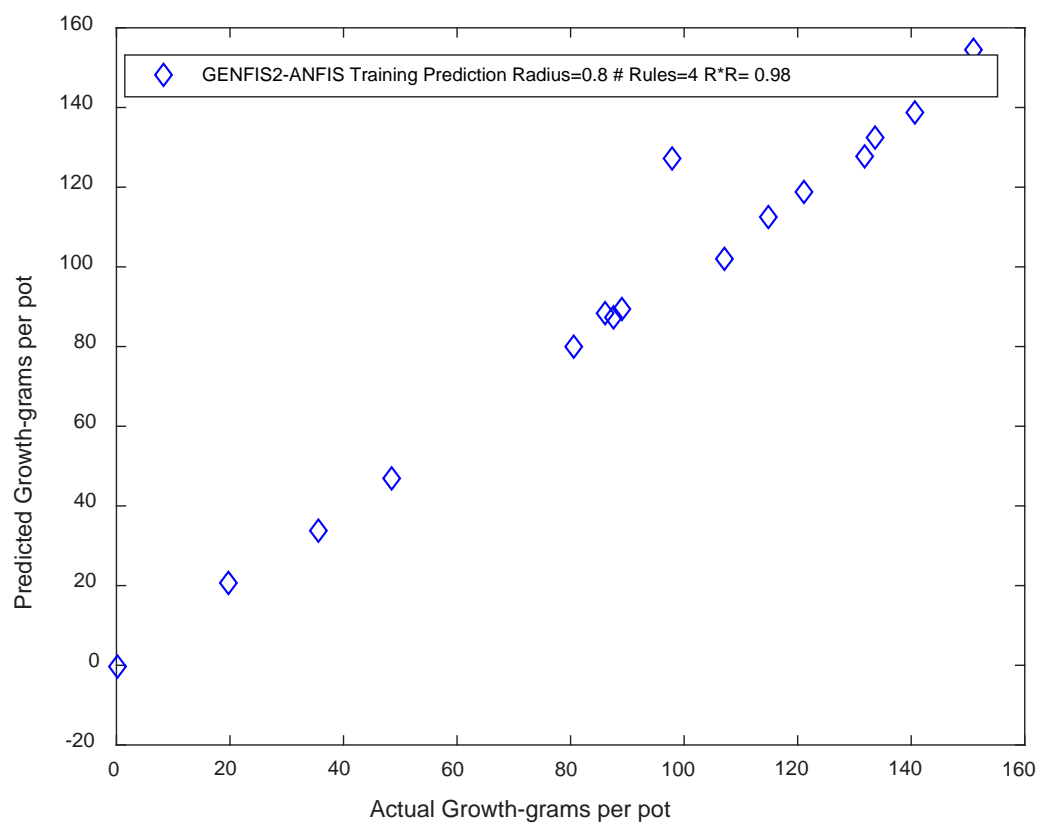

Figure 12. Predicted training total dry weights ( $\mathrm{g}$ / pot) of basil for fall 2016. The inputs were basil cultivars: 'Eleonora', a pesto basil, and 'Lime', and estimated electrical conductivity $\mu$ Siemens/cm.

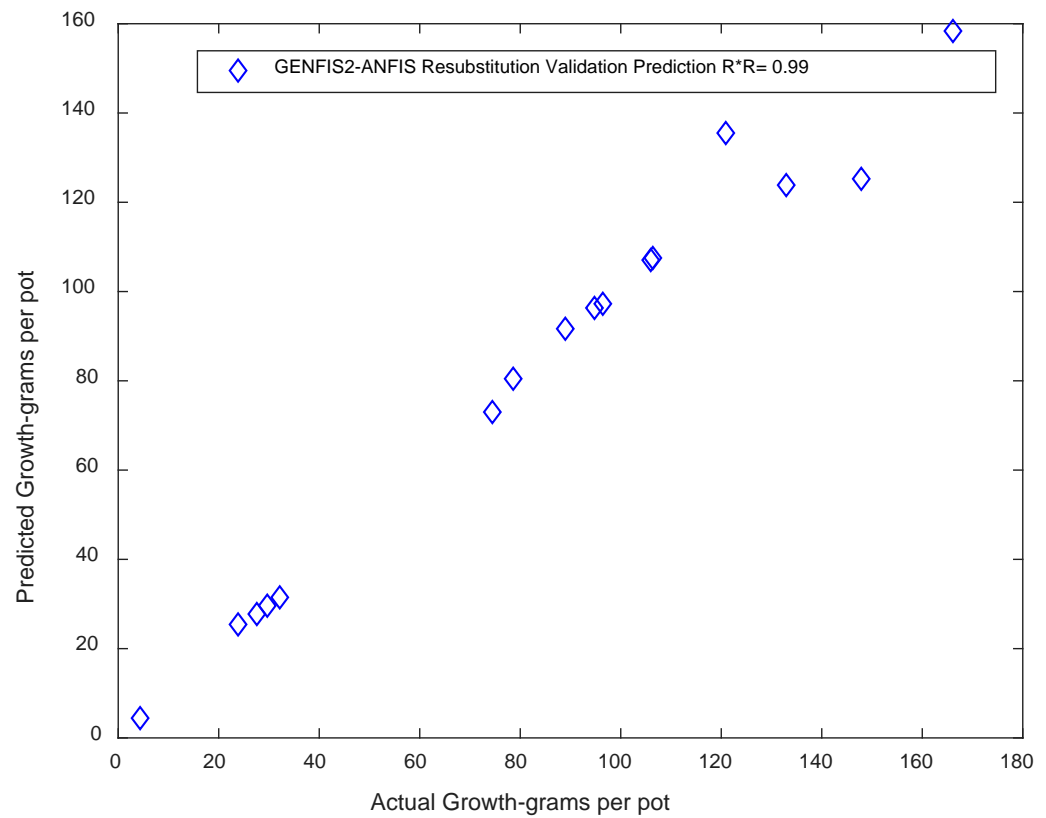

Figure 13. Internally validated by resubstitution total dry weights (g / pot) of basil for fall 2016. The inputs were basil cultivars of 'Eleonora' a pesto basil and 'Lime' and estimated electrical conductivity $\mu$ Siemens $/ \mathrm{cm}$. 


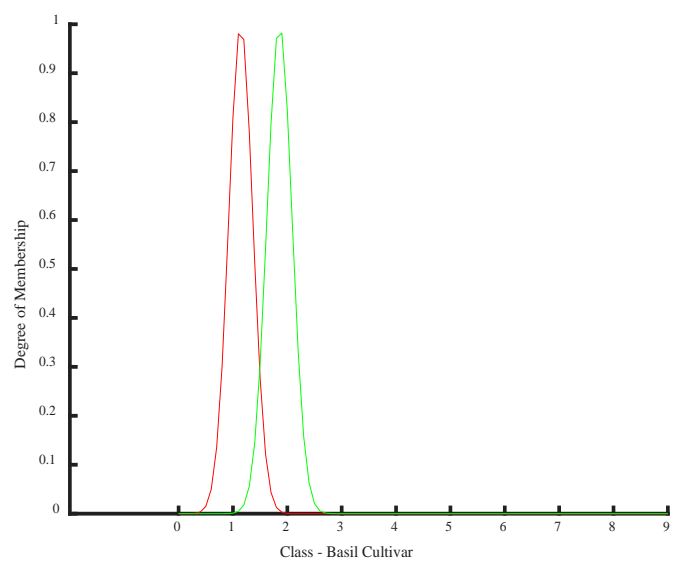

\begin{tabular}{|l|c|c|c|c}
\hline \multirow{2}{*}{$\begin{array}{c}\text { Confusion } \\
\text { Matrix }\end{array}$} & \multicolumn{3}{|c}{ Predicted Cultivars } \\
\cline { 2 - 5 } & $\begin{array}{c}1- \\
\text { 'Eleonora' }\end{array}$ & $\begin{array}{c}2- \\
\text { 'Lime' }\end{array}$ & $\begin{array}{c}\text { Rat } \epsilon \\
\%\end{array}$ \\
\hline \multirow{2}{*}{$\begin{array}{l}\text { Actual } \\
\text { Cultivars }\end{array}$} & $\begin{array}{c}1- \\
\text { 'Eleonora' }\end{array}$ & 14 & 2 & 87.5 \\
\cline { 2 - 5 } & $\begin{array}{c}2- \\
\text { Lime' }\end{array}$ & 1 & 15 & $93 . \varepsilon$ \\
\hline
\end{tabular}

Figure 14. Predicted 2016 cultivar classes as a set of two Gaussian Mamdani output membership functions, based on training FIS and subsequent validation data. Each cultivar class has a different color, but numbered according to Table 1. Confusion matrix: Classification rates for Basil Cultivars (fall 2016Data) - 90.6 \% Overall accuracy.

\section{Conclusions and Suggestions for Future research}

The results of the 2015 and 2016 experiments indicate that the Cap Mat system worked very well for basil production. Most growers will use the visual approach for assessing vegetative growth and any pest problems associated with that particular crop. The use of sensors like the GS3 has utility, but because of its expense would be difficult to instrument a large crop for commercial purposes. The GS3 sensor is useful for production studies to validate best practices for fertigation. The studies have shown that volumetric water contents of capillary-fed pots can be very steady and held around a 0.5 or 50 percent level. The control was a simple on/off timer system, say 2-3 times per photoperiod and while water and fertilizer was buffered within the absorptive fabric of the Cap Mat.

The data acquired from both the plants and electronic sensors was fairly simple, but fundamentally useful. Media and air temperatures of the greenhouse were continually monitored, but nothing really unusual was observed. The greenhouse Groton controller did its job, by adjusting heating below the bench to keep root and fertigation temperatures at desirable levels. However, the data also hints more complex plant growth relationships. Plant growth is not easily measured by non-intrusive methods (e.g. sampling dry matter is intrusive) A follow up experiment was performed during spring 2017, where in addition to sensor data, weekly canopy heights were measured. That data along with dry weight data could be analyzed to determine how effective the system is for predicting basil growth during winter-time greenhouse conditions.

The paper shows a couple of simple possible mathematical applications of modeling using fuzzy set theory and fuzzy classification approaches. In this case, sensor information was integrated with growth rates and cultivars. The biological community would like accurate predictive and model validation methods for quantitatively assessing plant growth production in a greenhouse. An advantage of the fuzzy inference system is that the natural language of the discipline could be incorporated as linguistic variables or fuzzy membership functions. Experimental data can be better addressed in horticultural terms, summarized, and expressed as a possible deductive inference.

There is a strong desire by the consumer for high quality, locally produced fruits, herbs and vegetables that are now only available on a seasonal basis. Through the use of extension tools and equipment, having optimal amount of solar radiation throughout the year, and the availability of a seasonal labor force, additional specialty crops should be explored. The challenge to winter production of medicinal, fruit and vegetable crops in Nebraska is outdoor temperatures, which may range from moderate to severe from one year to the next. Greenhouse producers in this region may utilize as much as $60 \%$ of their budget towards heating alone, indicating that sustainable methods that reduce this cost are critically needed for increased profits. Greenhouse designs providing reduced heating costs are 
not difficult. Predicting crop growth during the winter months, will allow producers to adjust temperatures and/or harvest earlier if plant growth is acceptable.

\section{References Cited}

1. Abyaneh, H.Z., A.M. Nia, M.B. Varkeshi, S. Marofi, and O. Kisi. 2011. Performance evaluation of ANN and ANFIS models for estimating garlic evapotranspiration. Journal of Irrigation and Drainage Engineering. 137(5): 280-286.

2. Al-Faraj A., G.E. Meyer, and G.L. Horst, 2001. A Crop Water Stress Index for Tall Fescue (Festuca arundinacea Schreb.) Irrigation Decision-making - A Fuzzy Logic Method, Computers and Electronics in Agriculture (Elsevier) 32(2):69-84.

3. Bezdek, J.C., C. Coray, R. Gunderson, and J. Watson, 1981. Detection and Characterization of Cluster Substructure I. Linear Structure: Fuzzy C-Lines. SIAM J. Appl. Math. 40(2):339-357.

4. Burnett, S., G.E. Meyer, M. Van Iersal, and R. Hanson, 2012. Save Water with Automation and Sensors. Greenhouse Grower, July: pp 1-3.

5. Center, B., Verma, B.P., 1997. A fuzzy photosynthesis model for tomato. Trans. ASAE 40 (3), 815821.

6. Gustafson, E.E., and W.C. Kessel, 1979. Fuzzy clustering with a fuzzy covariance matrix. IEEE CDC, San Diego:761 - 766.

7. Hoagland, L.A, L. Hodges, G.A. Helmers, J.R. Brandle, and C.A. Francis, 2008. Does the Corn/Soybean farmer have time for Alternative crops? Hortcience 43(4):1228.

8. Jang, Jyh-Shing R., (1993). ANFIS: Adaptive-Network-Based Fuzzy Inference System. IEEE Transactions on Systems, Man, and Cybernetics, 23(3):665-685.

9. Kurata, K., Eguchi, N., 1990. Machine learning of fuzzy rules for crop management in protected cultivation. Trans. ASAE 33 (4), 1360-1368.

10. Jang, Jyh-Shing R., 1993. ANFIS: Adaptive-Network-Based Fuzzy Inference System. IEEE Transactions on Systems, Man, and Cybernetics, 23(3):665-685.

11. Mamdani, E.H., Assilian, S., 1975. An experiment in linguistic synthesis with fuzzy logic controller. Int. .J. Man-Machine Stud. 7 (1), 1-13.

12. Meyer, G.E., E.T. Paparozzi, E.A. Walter-Shea, E.E. Blankenship, and S.A. Adams, 2012. An investigation of reflective mulches for use over capillary mat systems for winter-time greenhouse strawberry production. Engineering in Agriculture 28(2):271-279.

13. Meyer, G.E., E.T. Paparozzi, S. Adams, and D.S. Voltan, 2014. Evaluation of a Soilless Media Sensor for Managing Winter-time Greenhouse Strawberry Production on Cap Mat Systems, Paper Number 1913441, The American Society of Agricultural and Biological Engineering, St. Joseph, MI.

14. Osborn, C., M. Elizabeth Conley, Wan Wei and Ellen T. Paparozzi. 2016. Winter production of Basil (Ocimum basilicum) for fresh market and essential oil production.

15. Paparozzi, E.T., G.E. Meyer, 2012. The return of capillary mats. Greenhouse Grower, August: 78-84.

16. Ross, T.J., 2016. Fuzzy Logic with Engineering Applications. A.J. Wiley (Fourth Edition), 562 pp.

17. Rudnick, D.R., V. Sharma, G.E. Meyer, S. Irmak, 2015. Using Fuzzy Logic to Predict and Evaluate the Magnitude and Distribution of Precipitation on Rain fed Maize and Soybean Yields in Nebraska. Transactions of the ASABE, 58(5):1215-1229.

18. Takagi, T. and M. Sugeno, 1985. Fuzzy Identification of Systems and Its Applications to Modeling and Control. IEEE Transactions on Systems, Man, and Cybernetics, 15(1): 116-132.

19. Wei, Wan. 2016. Winter Greenhouse Production and Tissue Culture of Basil. Master of Science Thesis. University of Nebraska-Lincoln. Lincoln, Nebraska.

20. Zadeh, L A., 1975 The concept of a linguistic variable and its applications to approximate reasoningIII, Information Sciences, 9: 43-80.

21. Zadeh, L.A., 1975 The concept of a linguistic variable and its applications to approximate reasoningII, Information Sciences, 8: 301-357.

22. Zadeh, L.A., 1975. The concept of a linguistic variable and its applications to approximate reasoningI, Information Sciences, 8: 199-249.

23. Zadeh, L.A. (1978) Fuzzy sets as a basis for a theory of possibility. Fuzzy Sets and Systems 1: 3-28.

24. Zadeh, L.A. 1978. Fuzzy sets as a basis for a theory of possibility. Fuzzy Sets and Systems 1: 3-28. 


\section{Appendix - Greenhouse Environmental Time Series Data}

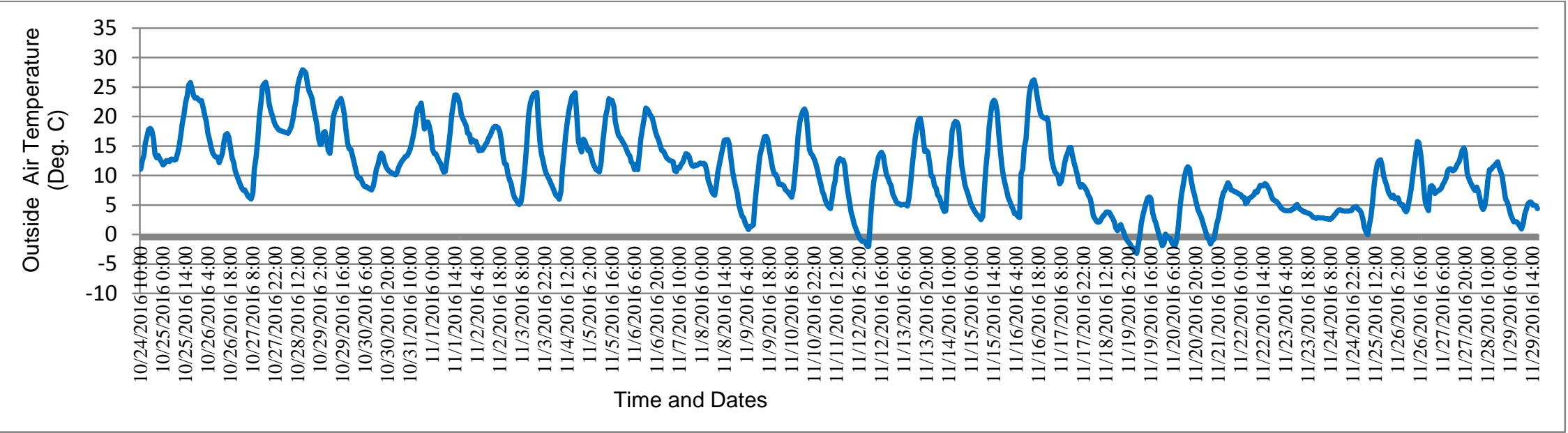

Figure 15. Fall 2016 Outside air temperatures.

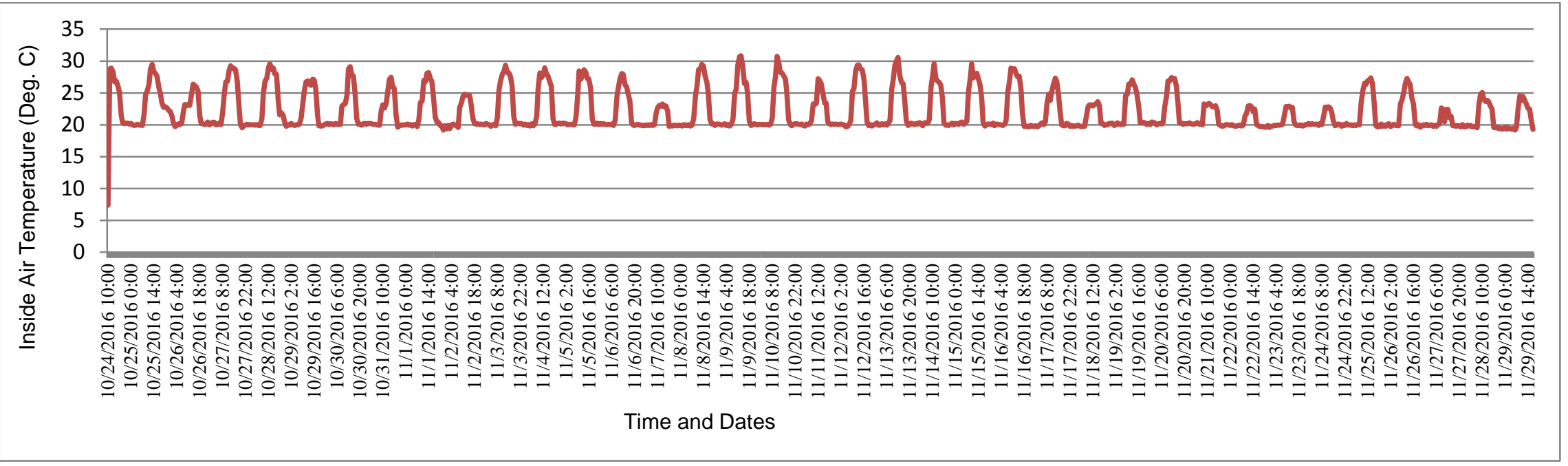

Figure 16. Fall 2016 Inside greenhouse air temperatures. 


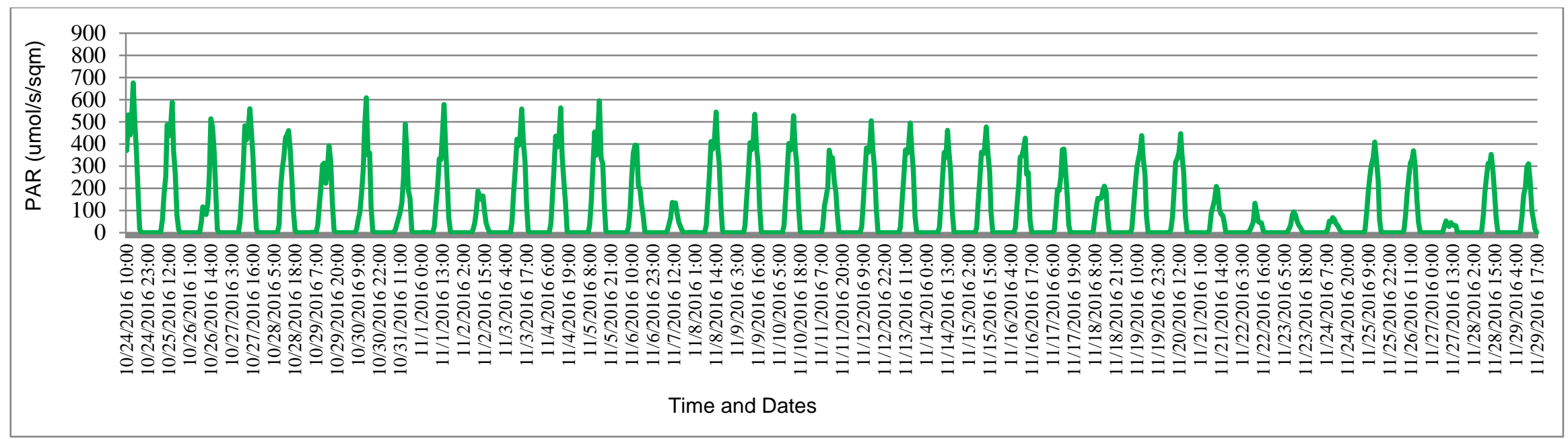

Figure 17. Fall 2016 Photosynthetically Active Radiation (PAR), Middle of greenhouse.

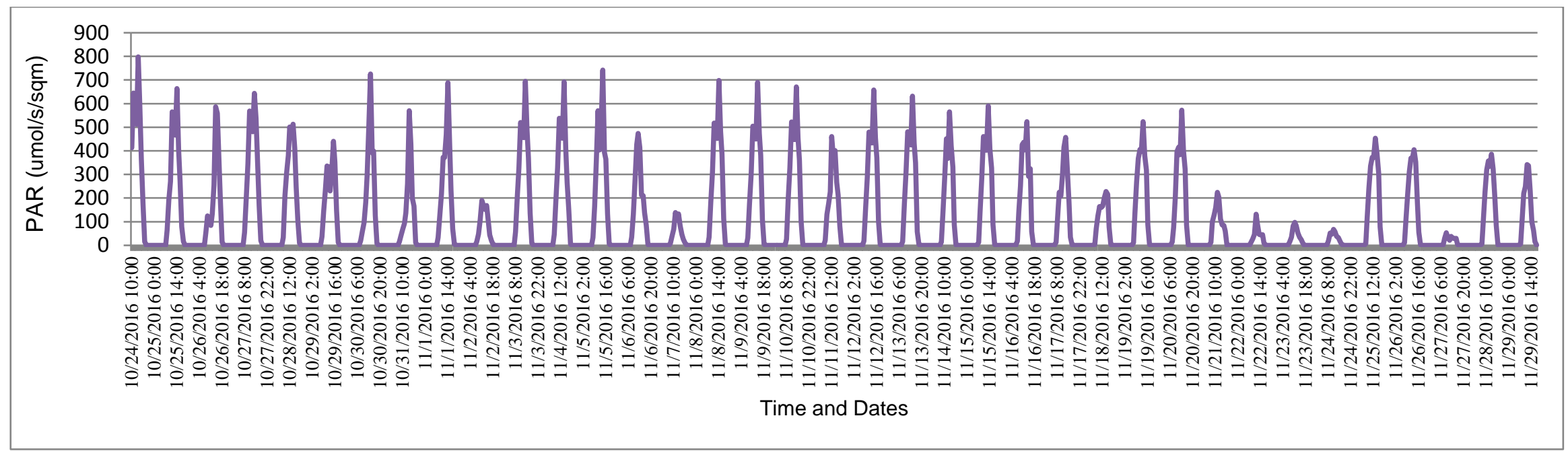

Figure 18. Fall 2016 Photosynthetically Active Radiation (PAR), South end of greenhouse. 


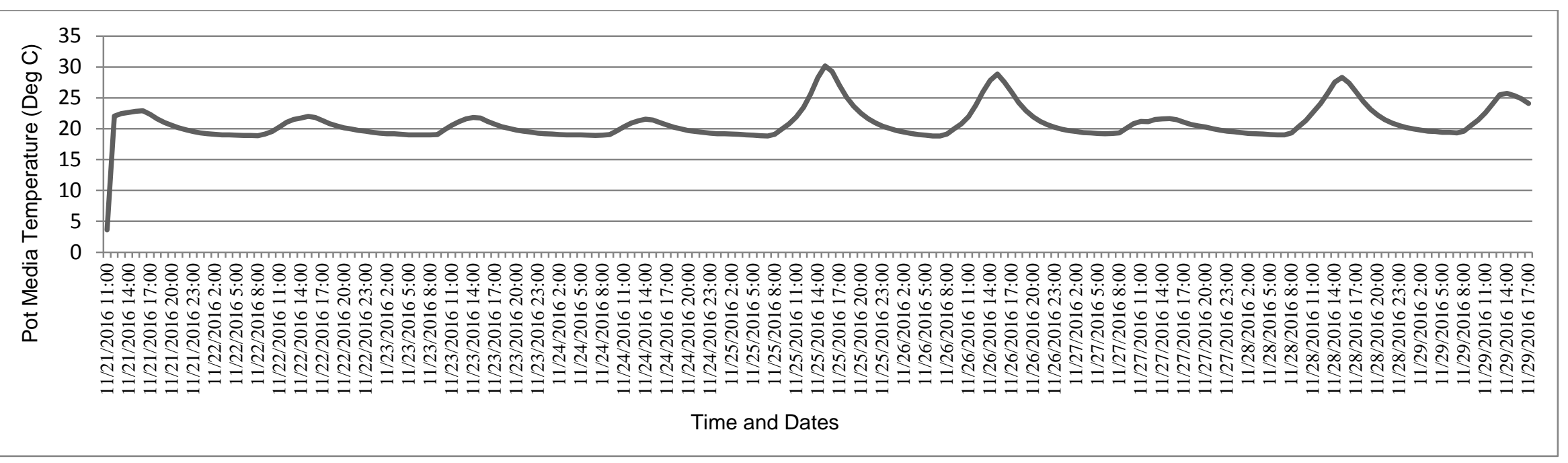

Figure 19. Fall 2016 Media Temperatures, Sensor E.

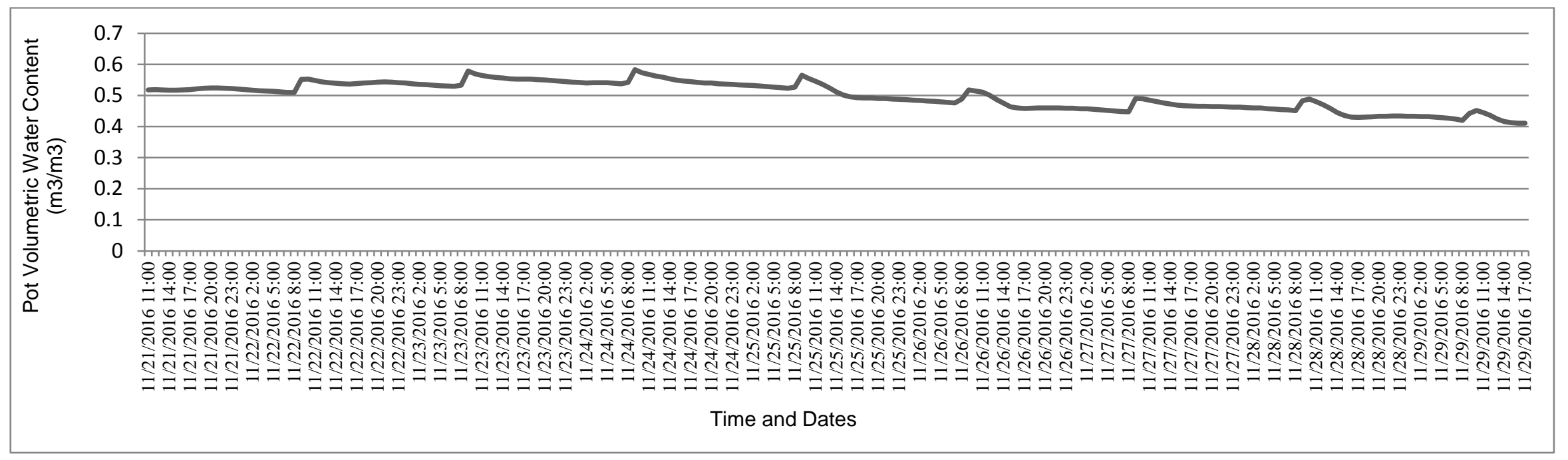

Figure 20. Fall 2016 Volumetric Water Content, Sensor E 


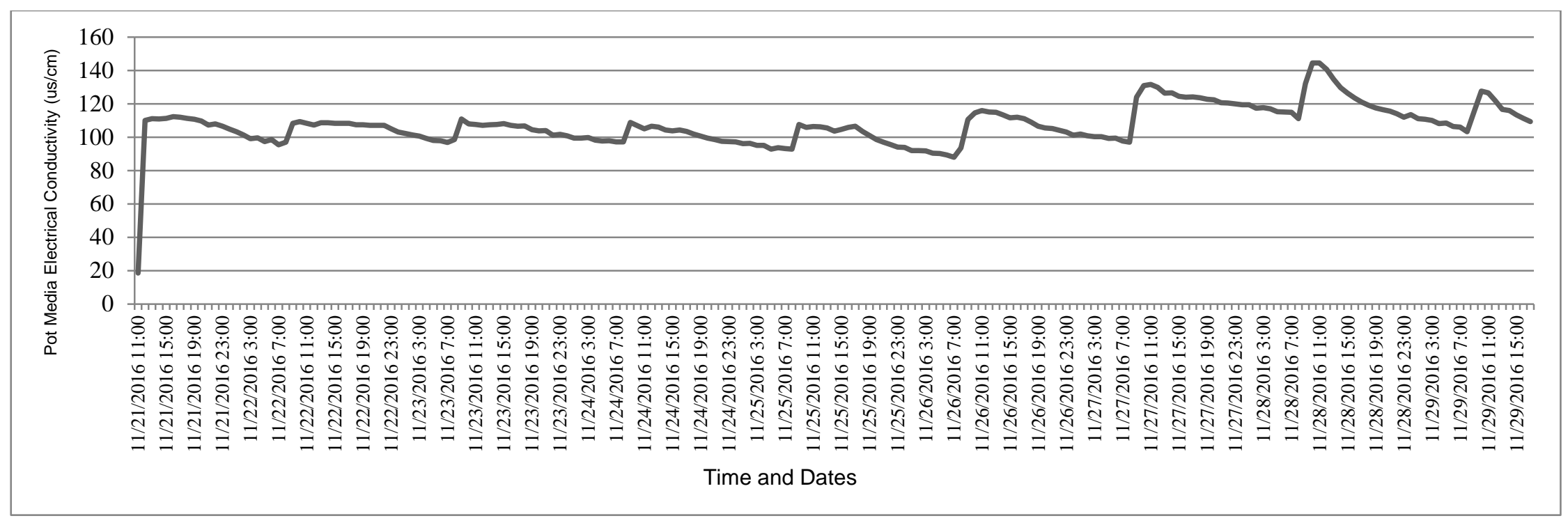

Figure 21. Fall 2016 Media Electrical Conductivity, Sensor E. 